\title{
A PRESENÇA DO IKEBANA IKENOBÔ NO BRASIL
}

Valderson Cuiabano Silvério de Souza

RESUMO: Nosso objetivo é apresentar uma cronologia da arte floral japonesa no Brasil, em especial, da presença do Ikebana Ikenobô. Os primeiros registros datam da década de 1930, e dizem respeito a aulas para a comunidade da Colônia de Itaquera, SP. Durante as comemorações do IV ${ }^{\circ}$ Centenário da cidade de São Paulo (1954) e com a inauguração do Pavilhão Japonês no Parque do Ibirapuera, a vinda de mestres do Japão inicia a difusão do Ikebana para os brasileiros. O estabelecimento da primeira filial do Ikenobô no Brasil se deu em 1960 e antecede a criação da Associação de Ikebana do Brasil. A partir do Ikenobo Kadokai Nambei Shibu foram criadas outras três filiais, aumentando a influência e a contribuição do Ikebana para o desenvolvimento do mercado floral brasileiro e para a criação de um estilo floral nipo-brasileiro.

PALAVRAS-CHAVE: Cultura Japonesa, Ikebana Ikenobô, Ikebana no Brasil.

ABSTRACT: Our purpose is to present a chronology about Japanese floral art in Brazil, in special Ikebana Ikenobô's presence. The early registers dated from the Thirties, and said about ikebana classes to the community of Itaquera Colony, in São Paulo. During the IV Centennial of São Paulo (1954), the Japanese Pavilion of Ibirapuera Park opening and the arrival of Floral Art Masters from Japan, spread Ikebana into Brazilian people. The first Ikebana Ikenobô branch in Brazil was settled in 1960 and precedes the Ikebana Association of Brazil. From Ikenobô Kadokai Nambei Shibu was formed three others branches, increasing the influence and contribution of Ikebana in the development of Brazilian floral market and the design of Brazilian-Japanese floral style.

KEYWORDS: Japanese Culture, Ikenobô Ikebana, Ikebana in Brazil. 
O termo Ikebana e a prática da arte floral japonesa se tornam mais conhecidos no Brasil a partir do pós-guerra. Havia aqui a representação das seguintes escolas: Escola Shogetsudo-Koryu - prof Fumi Naiki; Escola Yamato-Ryu - dissidência da Escola Ohara (1938) - prof. Rigiku Kikuchi; Escola Ikenobô - (1945) - prof . Ei Fujiwara; e a Escola Misho-Ryu - (1946) - prof ${ }^{a}$ Kiseho Ikeda. As outras escolas de Ikebana no Brasil foram criadas posteriormente, já na segunda metade do século XX.

A tradição da arte floral do Ikebana Ikenobo chegou ao Brasil em 1933 (ano 8 da era Showa) com a professora Ei Fujiwara, que imigrou para o Brasil nesse mesmo ano. Ela, no ano anterior, recebera o título e o diploma Waki Kyôuju 1. 脇教授 一 - Instrutor de Ikebana de $1^{\circ}$ grau, que lhe permitia transmitir os conhecimentos e lhe assegurava a autorização para emitir certificados reconhecidos pela sede da academia. Em 1935, a professora Fujiwara organizou suas primeiras turmas de alunos, dando início às aulas de Ikebana Ikenobô na colônia japonesa de Itaquera, São Paulo. Em 1950, passou a residir na cidade de São Paulo, aumentando consideravelmente o número de alunos e a divulgação do Ikebana como a arte floral japonesa por excelência. Em 1953 (ano 28 da era Showa) ela recebeu o título e grau Sei Kyôuju 1. 正教授 - - Professor Titular de $1^{\circ}$ grau. A grande distância entre o Brasil e o Japão, o problema das estações diferenciadas e dos diversos calendários, e as questões administrativas a respeito do sistema Iemoto levaram-na, em 1963, a romper com a escola Ikenobô.

Esse episódio propiciou um fato inédito: o nascimento da única escola de Ikebana criada fora do território japonês - a Associação Cultural de Ikebana Koguetsu Ryu - Kado Kooguetsu Ryu 華道香月流, registrada no Ministério da Educação da República Federativa do Brasil. Em abril de 1964 aconteceu a fundação da Associação. Pode-se perceber que o seu desligamento da Escola Ikenobô do Japão se deu apenas administrativamente, pois de fato seu estilo baseava-se nos conceitos estéticos do Ikenobô, assim como em suas técnicas de composição e manutenção. Seu aspecto inovador foi introduzir a utilização, ainda que muito discreta, de espécies vegetais nativos do Brasil, dando início a um processo de aculturação da arte do arranjo floral japonês em nosso território.

No ano de 1953 chegou ao Brasil o professor Hirotoshi Seki, monge budista !, que era reconhecido como professor de "grau especial da escola Ikenobô" Seu trabalho veio a se tornar muito importante na divulgação não apenas da arte floral, mas também de toda a cultura japonesa em nosso território. Em seu livro - Ikebana Ikenobo ${ }^{2}$, no prefácio intitulado "O homem e a flor" escreveu:

1. Acreditamos ser o prof. Seki um monge budista da tradição Soto Zen, pois veio para trabalhar no templo Bushinji da Rua São Joaquim; e estabeleceu sua residência no bairro de Pinheiros, na Rua Fradique Coutinho, na capital paulista.

2. SEKI, Hirotoshi - "Ikebana" Ikenobô, publicação do autor / Copiadora Geracópia, São Paulo 1961 - cópia xérox do original. 
Tive a honra de ser designado pela Escola IKENOBÔ, onde me formei, e pelos seguidores deste estilo, como docente desta arte e transferido para este tão encantador pais, o Brasil.

Logo que cheguei, surpreendi-me ao encontrar na prática desta arte floral uma tendência bastante adversa àquelas padronizadas; sendo assim esforcei-me e ora me esforço para difundir um conceito exato do que seja o estilo IKENOBÔ. (SEKI, 1961, p.2)

Em 1954, por ocasião dos festejos do IV centenário da cidade de São Paulo, o governo do Japão enviou uma comitiva cultural organizada pelo Ministério das Relações Exteriores; dela fazia parte a professora Noriko Nakamura (posteriormente conhecida pelo nome de Noriko Ono), na época representante da Escola Sogetsu. Sua missão era realizar demonstrações de Ikebana, no Pavilhão Japonês do Parque do Ibirapuera recém inaugurado. A professora Ono, de certo modo, foi a responsável pela divulgação do termo Ikebana entre os brasileiros graças à intensa divulgação, pelos meios de comunicação, de suas realizações. Ela, posteriormente, criou sua própria escola, denominada Kokusai Ikebana (Ikebana Internacional) e considerou seu período paulistano como o turning point de seu trabalho como artista, como professora, e divulgadora da arte floral japonesa em todo o mundo.

Ao longo da década de 1950 e, especialmente após os festejos do IV centenário de São Paulo, o mestre Seki investiu consideravelmente no fortalecimento de um intercâmbio cultural com a Universidade de São Paulo, com o Museu de Arte de São Paulo, com os intelectuais e com a sociedade dos descendentes e não-descendentes dos japoneses aqui estabelecidos. Seu curso básico de Ikebana buscava criar interesse pelos aspectos simbólicos e religiosos da cultura japonesa, estudando essas relações por meio de cores, formas, da arte e do artesanato tradicional japonês. Do mesmo modo, é nesse período que a arte floral japonesa adquire destaque nos meios de comunicação brasileiros. Publicações especializadas editam páginas especiais sobre o assunto, especialmente a revista Casa e Jardim, com uma série de artigos a respeito do ensino de técnicas e arranjos básicos de Ikebana, coordenados pela professora Ei Fujiwara; assim como uma coluna de Ikebana criada na "Página da Mulher". do Jornal Paulista.

A oficialização do ensino do Ikebana Ikenobô no Brasil acontece em 1960 com a fundação da Kado Iemoto Ikenobô Kadokai Nambei Shibu, tendo como Diretor Regional o professor Hirotoshi Seki e como Vice-Diretora a Sra. Hideko Akamo. Nos registros da associação está assinalado o dia 23 de novembro de 1960 como a data de sua fundação. O início da associação e as suas primeiras aulas aconteceram na casa do professor Seki, na casa da professora Ishi Kanazawa, e no edifício antigo do Bunkyo - na época, denominado de Sociedade da Cultura Japonesa de São Paulo, e atualmente conhecido como Sociedade Brasileira de Cultura Japonesa. 
Para comemorar a inauguração de sua sede, o jornal São Paulo Shimbun organizou uma exposição de Ikebana. Como preparação para o evento foi realizada uma ampla cobertura jornalística, apresentando os professores e as respectivas escolas de Ikebana atuantes em São Paulo. No dia 28 de abril de 1961 foi inaugurada a "Exposição Coletiva das Escolas de Ikebana" As dez escolas e quinze mestres que participaram deste evento foram: MishoRyu (Kiseho Ikeda), Yamato-Ryu (Houen Kikuchi), Seigetsu-Ryu (Kaoru Yano), Ikenobô (Hirotoshi Seki, Kyoko Shingu), Kokusai Ikebana (Suketaro Okada, Michiko Takizawa, Haruno Iwama), Sogetsu-Ryu (Shunpo e Shunpa Kuroda, Shikoo Kato), Shoko Misho-Ryu (Ichiko Yasuda), Nisshin-Ryu (Shoshin Nishizawa), Ohara-Ryu (Hoko Yano), Shogetsudo Koryu (Fumi Naiki), e a participação especial da escola Enshu-Ryu (Tsutaya Shirota).

Em vinte e seis de janeiro de 1962 é fundada a Associação de Ikebana do Brasil - Ikebana Kyokai - que reúne as escolas dos diferentes estilos atuantes no Brasil. Foram definidos três objetivos como fundamentais para a associação:

1. Divulgar amplamente na sociedade brasileira o Ikebana, peculiaridade japonesa, para o intercâmbio cultural entre Brasil e Japão.

2. Objetivar a confraternização mútua entre os associados para o aprimoramento do Kadô.

3. Proporcionar incentivos diretos nas exposições realizadas pelas respectivas escolas e, também, na realização das exposições coletivas.

O início da década de 1960 foi o período de divulgação e consolidação da Kado Iemoto Ikenobô Nambei Shibu em território nacional, o professor Seki realizou simpósios e palestras com professores de universidades brasileiras e japonesas, buscando ampliar o conhecimento e interesse dos alunos a respeito da arte de um modo geral. Como um exemplo dessa colaboração e da qualidade desses eventos, encontramos o registro de um ciclo de palestras realizado por intelectuais brasileiros e por professores da Escola de Belas Artes de Tókio, sob sua coordenação. Nesse ano de 1963, o Nambei Shibu conta com a sede estabelecida em São Paulo, e com filiais em Marília, Tupã, Mogi das Cruzes e no estado do Paraná. Um fato importante para a Associação foi participar da realização de uma exposição de Ikebana comemorativa ao terceiro ano de fundação da nova capital brasileira, o que ocorreu no mês de fevereiro em Brasília, DF.

Este período histórico é de extrema importância no estabelecimento e consolidação do Ikebana no Brasil. O termo, e as próprias formas da arte floral japonesa ganham popularidade nacional, embalada pela onda de "modernização" gerada pela inauguração da nova capital, pela bossa nova, pelo cinema novo, enfim o Ikebana se integrava como o "arranjo floral moderno" a essa febre de novidades.

O ano de 1964 foi significativo tanto para o Brasil como para o Ikebana Ikenobô. Logo após o golpe militar, no mês de abril, é inaugurado o novo prédio do Bunkyo no bairro da Liberdade em São Paulo. Para celebrar o evento é realizada uma exposição conjunta 
das escolas de Ikebana. As atividades da escola Nambei Shibu durante o ano de 1964 se concentram principalmente no estado do Paraná, em razão do crescente número de alunos e de comunidades interessadas em aulas de Ikebana Ikenobô. No começo do mês de outubro a escola Nambei Shibu realiza sua exposição anual no Pavilhão japonês do Ibirapuera. Em outubro desse ano, o prof. Seki retorna ao Japão e a direção e as atividades do Nambei Shibu foram assumidas pela professora Hideko Akamo, Vice-Presidente da Associação e responsável, também, pelas aulas de shodô (caligrafia japonesa). $O$ ano terminou com a participação da escola em uma exposição comemorativa à abertura dos festejos do IV Centenário de fundação da cidade do Rio de Janeiro.

A orientação pedagógica da escola de Ikebana Ikenobô Nambei Shibu, antes posicionada como uma escola de artes assumiu, com a nova direção, um posicionamento que caracterizava a maioria das escolas de arte floral tanto no Japão e na maioria dos países, a característica de ser básicamente uma "escola de senhoritas ou clube de senhoras" Essa postura adotada pela professora Akamo, porém, teve seu lado positivo. Foi estabelecida na escola uma preocupação constante em realizar ações sociais, seja por meio de trabalhos voluntários seja por meio de doações e ações beneficentes periódicas em favor de instituições filantrópicas e assistenciais; essas práticas estão ainda em atividade.

A partir do ano de 1966 passaram a ser realizados arranjos de Ikebana nos cinemas da Liberdade nas pré-estréias dos filmes japoneses, e as ações culturais realizadas pelos associados da escola Nambei Shibu se concentraram em eventos tais como a "Primeira flor do Ano" - Hatsuike; participações em exposições e bazares voltados para a produção agrícola como os eventos da Cooperativa Agrícola de Cotia, a Festa da Batata, sem esquecer, é claro, da realização de uma grande exposição anual dos professores e alunos.

No ano de 1968 aconteceu um fato importante para a difusão do Ikebana Ikenobô no Brasil; no mês de abril ocorreu a fundação do Instituto de Ikebana Ikenobô do Brasil. Fundado por membros dissidentes do núcleo Ikenobô da Associação de Ikebana do Brasil, teve a professora Kiyoko Shingu como sua primeira Diretora-Presidente, e como VicePresidente a professora Kimiko Abe. Em agosto desse mesmo ano a nova escola realizou a sua primeira exposição, no salão nobre do Bunkyo, e no ano seguinte de 1969 realizou uma exposição de Ikebana no Palácio da Alvorada, para esposas de diplomatas, e uma outra exposição, aberta ao público, no Hotel Nacional de Brasília.

No começo da década de 1970 começaram os planejamentos para a comemoração do $10^{\circ}$ aniversário da Associação Nambei Shibu, e em 26 de novembro de 1971 foi aberta a exposição comemorativa ao décimo aniversário, na Fundação Bienal de São Paulo, com a presença do grão mestre Sen'ei Ikenobô e comitiva, e em 29 de novembro de 1971 foi realizada uma demonstração de Ikebana Ikenobo no edificio do Ministério da Educação e Cultura em Brasília, DF. 
Um fato importante acontece neste período no que diz respeito às novas gerações, que foi a parceria estabelecida com a Escola Shôhaku ${ }^{3}$. Desde essa época até os dias atuais uma professora do Nambei Shibu é a responsável pelas aulas de Ikebana oferecida aos alunos de todos os níveis desta instituição. É uma garantia de continuidade e de respeito à milenar arte do arranjo floral japonês. Outro dado bastante positivo para o propósito da escola aconteceu no ano de 1978, quando do retorno da Associação Nambei Shibu à participação na Associação de Ikebana do Brasil (Ikebana Kyokai), após 15 anos de afastamento.

Durante a década de 1980 continuaram os eventos especiais como a Cerimônia da $1^{a}$ Flor do Ano - Hatsuike, e a exposição anual de Ikebana e Caligrafia - Shodo, na sede do Bunkyo. No ano de 1981 a Associação Nambei Shibu organizou pela primeira vez o bazar anual da Associação, que passou desde então a ser uma atividade anual de intercâmbio social, com a presença de artistas plásticos, especialmente de ceramistas que produzem vasos para a prática do Ikebana, assim como de comerciantes e bazaristas de produtos artesanais e semi industrializados. No mês de setembro saiu de São Paulo para Buenos Aires, Argentina, uma caravana de professores e alunos liderados pela professora Akamo com o objetivo de participar de uma exposição comemorativa do Ikebana Ikenobô da Argentina. A participação era mais do que justificada, pois a Associação Nambei Shibu é a instituição que divulgou e implantou o Ikebana Ikenobô na Argentina, no Paraguai e no Peru.

Também para o Instituto de Ikebana Ikenobô do Brasil, e para o Ikebana de modo geral aqui no Brasil, a década de 1980 foi muito importante. Em 1981 a Presidente do Brasil Shibu, a senhora Kyoko Shingu iniciou a ministrar aulas no curso de extensão universitária de Ikebana oferecido pela Universidade de São Paulo, nas dependências da Casa de Cultura Japonesa da USP. Esse curso, assim como o de Cerimônia do Chá, é atualmente oferecido pelo Departamento de Letras Orientais da Faculdade de Filosofia, Letras e Ciências Humanas da USP e tem auxiliado em sua difusão entre acadêmicos e funcionários da universidade, tendo sempre constante procura. No mesmo ano de 1981, o Brasil Shibu fundou sua filial em Pereira Barreto, SP.

O ano de 1984 foi determinante para a história do Nambei Shibu, em junho do corrente ano faleceu a professora Akamo, presidente da Associação. Em razão do acontecido, a estrutura montada para o funcionamento da escola passou por uma revisão. No mês de agosto de 1984 uma Assembléia Geral Extraordinária elegeu como Presidente da Associação

3 A Escola de Línguas "Shôhaku" foi fundada em 1953 pela professora Mariko Kawamura. Em 1982, graças a união de alguns professores que seguiam a linha pedagógica do professor Oshiman Junji, a escola passou a adotar o nome de Escola de Línguas Oshiman. Em 1993 a escola foi reconhecida pelos órgãos oficiais de educação, recebendo o nome de Escola de Educação Infantil e Ensino Fundamental Professor Oshiman, e em 1996 foi fundada a Associação Cultural Oshiman. Atualmente a escola está situada no bairro da Aclimação em São Paulo. A professora Mine Uchida foi durante muitos anos a responsável pelas aulas de Ikebana nessa instituição, e desde 2001 as aulas estão sob a responsabilidade da professora Kazue Takada, atual $1^{\text {a }}$ VicePresidente da Associação Nambei Shibu. 
o Senhor Shokichi Shibukawa, como $1^{\text {a }}$ Vice-Presidente a professora Ishi Kanazawa, e como $2^{\text {a }}$ Vice-Presidente a professora Mine Uchida. Podemos considerar que a fase pioneira e de implantação da escola completou aqui uma etapa. Um novo ciclo começou a partir dessa transformação e isto pode ser percebido pela própria instituição da pessoa jurídica da entidade, que deixa de ser apenas uma escola filiada ao Japão e à Associação de Ikebana do Brasil. Em 14 de dezembro de 1984 foi registrada oficialmente a Associação de Arte Floral Kado Iemoto Ikenobô Nambei Shibu, situada na cidade de São Paulo, no bairro da Liberdade.

Desapareceram de modo gradual os velhos quadros mantenedores do sistema japonês, e iniciou-se, ainda que de forma tímida e bastante irregular, um esboço de sistema participativo na diretoria da instituição, com o rodízio e preparação dos novos quadros diretores. Os associados, a partir de um determinado tempo de aulas e de participação, começam a ser lentamente introduzidos nos quadros da diretoria e, desse modo, são preparados como alunos de um "curso especial de administração" para virem, em um futuro próximo, dirigir a escola. O conceito de "associação" passou a ser respeitado e reconhecido como marca do novo tempo. Essa prática vem sendo mantida até os dias de hoje, por aqueles associados que se permitem participar e desenvolver um trabalho de transmissão de conhecimento e de cultura. A grande maioria, porém, mantêm apenas um vínculo simbólico e econômico (pagamento de anuidades) com a instituição. Os professores se esforçam para tornar seus alunos associados, mas a participação desses alunos nas atividades da associação e até mesmo em suas exposições já é uma outra situação, com motivos os mais variados para justificar as ausências e impossibilidades.

As transformações ocorridas na Associação Nambei Shibu em 1984 levaram a professora Emilia Tanaka a pedir seu desligamento da mesma, assim como também solicitar ao lemoto a autorização para criar uma nova filial do Ikebana Ikenobô aqui no Brasil. Essa autorização chegou do Japão, e no dia 15 de novembro desse ano iniciaram-se as atividades da Associação de Ikebana Kado Ikenobô Tatibana da América Latina, a terceira filial do Ikebana Ikenobô em nosso país, tendo como fundadora e Presidente a própria professora Emilia Tanaka.

Já para a Associação Nambei Shibu o "novo tempo" em suas atividades foi marcado pela aquisição de sua sede à Avenida Liberdade 486 sala 1210, em 26 de abril de 1985 . Em 09 de agosto de 1985 começam a ser ministradas as primeiras aulas de Ikebana Ikenobô na nova sede. No ano de 1987 foi pedido o desligamento dos membros da filial do Paraná da associação Nambei Shibu, com o propósito de formar um número suficiente de membros para a criação do atual Instituto de Ikebana Ikenobô América do Sul Paranaense, sob a direção da professora Takako Kawasaki. A autorização e registro da nova filial do Ikebana Ikenobô no Brasil, a quarta escola em funcionamento, chegou do Japão em setembro desse ano.

Ainda em 1987 aconteceu o retorno da professora Kiyoko Shingu, fundadora e presidente do Ikebana Ikenobô do Brasil, ao Japão. Foi eleita presidente do Instituto a 
professora Kimiko Abe, com o objetivo de continuar com as atividades que já vinham sendo desenvolvidas por esta escola. A década de 1980 foi terminando com mudanças na diretoria do Nambei Shibu. Em 1989 as comemorações anuais ou não foram realizadas, como o evento da $1^{\mathrm{a}}$ Flor do Ano, ou tiveram seu brilho diminú́do por causa do falecimento do imperador Showa (Hiroito). Porém em setembro desse mesmo ano, a associação realizou nos espaços do novo Centro Cultural São Paulo, no bairro do Paraíso, uma exposição comemorativa do trigésimo aniversário do Nambei Shibu, que contou com a participação do grão-mestre e de convidados vindos especialmente do Japão. Ė necessário assinalar que a partir desse evento as exposições anuais de Ikebana do Nambei Shibu passaram a ser realizadas nos espaços de exposição do Centro Cultural São Paulo, local privilegiado para a difusão dessa arte junto ao público paulistano, e raras foram as realizações efetuadas pela Associação fora deste local.

A década de 1990 manteve as práticas que vinham sendo desenvolvidas pelas escolas de Ikebana, no que diz respeito às aulas, exposições e a realização de eventos beneficentes. Foi este período do estabelecimento de uma espécie de sistematização de procedimentos e realizações, pois as três filiais do Ikebana Ikenobô no Brasil, estabelecidas na cidade de São Paulo, conseguiram criar suas próprias rotinas de realizações e marcar as características de suas respectivas personalidades, tanto no campo artístico como na utilização de determinados espaços culturais da cidade. Importante registrar que em todas as representantes do Ikebana Ikenobô aconteceu uma onda renovadora, assegurada pela presença cada vez maior de alunos não-descendentes, e também pela intensificação do discurso oficial adotado pelo Iemoto ao longo de toda a década no sentido da internacionalização e de uma postura mais globalizante da arte floral japonesa. A presença de alunos gaijin (termo japonês para "estrangeiro") levou a uma nova interpretação da pedagogia estabelecida pela sede central em Kyôto desde o início da era Edo. Seja aqui no Brasil, seja em outros países do ocidente, tornou-se necessário adaptar as regras e conceitos orientais às culturas locais.

E foi também durante a primeira metade da década de 1990, que iniciamos um trabalho de divulgação do Ikebana para os brasileiros, especialmente para os não descendentes de japoneses. Para eles, em sua grande maioria, esta manifestação artística se constituía - e ainda constitui - uma espécie de enigma paradoxal. A constituição artística do Ikebana se opõe frontalmente aos parâmetros "oficiais" da obra de arte, por causa de sua fragilidade temporal (seu tempo de vida é efêmero), de sua dificuldade em se transformar em mercadoria comercializável, assim como pela sua complexidade técnica e impossibilidade de conservação. Estas considerações, aliadas ao desconhecimento dos conceitos estéticos japoneses, fizeram com que muitos especialistas em arte e uma parte do público, seja aqui no Brasil ou no exterior, desconsiderem o Ikebana enquanto arte e o vissem como mera manifestação folclórica. 
Talvez sejamos os primeiros homens não descendentes de japoneses a possuir o título e grau Sei Kyôuju 1. 正教授 - - Professor Titular de $1^{\circ}$ grau, outorgado pelo $45^{\circ}$ Iemoto da escola Ikenobô - Sen ei Ikenobô, na América do Sul, especialistas no mais tradicional estilo de Ikebana. Muito mais do que nos envaidecer, esse fato reafirma o caráter pioneiro do Ikebana Ikenobô no mundo globalizado; assim como nos outorga a missão de realizar a interface entre o Oriente e a comunidade brasileira.

Esperamos e propomos, com a realização deste, um novo olhar e uma nova consideração, seja em relação às políticas culturais e de incentivo adotadas pelas instituições oficiais, seja por parte da própria comunidade nipo-brasileira. Se existem brasileiros (descendentes ou não) que interessam pelas origens e tradições da arte japonesa, isso se deve à presença e atuação dos seus representantes nas terras do Brasil, que souberam com trabalho e talento mostrar o que de mais belo existe em suas tradições culturais.

\section{Bibliografia}

ABE, Kimiko; KAWAMURA, Tokuko. Ikebana, arte e criação no estilo Ikenobo. São Paulo: Aliança Cultural Brasil Japão, 1993.

ASSOCIAÇÃO DE IKEBANA DO BRASIL. História de 40 anos da Associação de

Ikebana do Brasil. São Paulo: Edição do autor, 2002.

FUJIWARA, Ei. Introdução ao estilo "Kooguetsu-Ryu" São Paulo: Associação Cultural de Ikebana Kooguetsu-Ryu, 1989.

HANDA, Tomoo. O Imigrante Japonês no Brasil - História de sua vida no Brasil. São Paulo: T.A. Queiroz Ed. / Centro de Estudos Nipo-brasileiros, 1987.

MYAZAKI, Nobue (org.). A cultura japonesa pré-industrial. São Paulo: Edusp, 1998.

OHNO, Noriko. Poesy in life trough flowers. Kamakura Shobo, 1985.

PLUTSCHOW, Herbert E. Historical Chanoyu - 茶の湯の歴史. Tóquio: The Japan Times Ltd, 1986.

SEKI, Hirotoshi. Ikebana Ikenobo. São Paulo: edição do autor, 1961.

TANAKA, Emilia et alii. História de $\mathbf{4 0}$ anos da Associação de Ikèbana do Brasil. São Paulo: Bunkyo, 2002.

YAMASHIRO, José. História da Cultura Japonesa. São Paulo: IBDC, 1986. 